\title{
Effect of mineral injectable supplementation with phosphorus, selenium, magnesium, copper and potassium on cyclicity resumption and pregnancy rate of Bos taurus or crossbreed beef cows during the protocol of FTAI
}

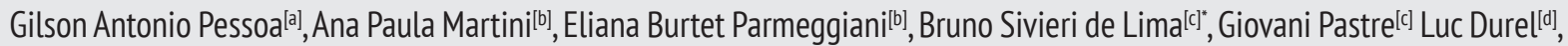
Gustave Decuadro-Hansen ${ }^{[e]}$

\author{
[a] Universidade de Caxias do Sul (UCS), Caxias do Sul, RS, Brazil \\ [b] Universidade Federal de Santa Maria (UFSM), Santa Maria, RS, Brazil \\ [c] Virbac do Brasil, São Paulo, SP, Brazil \\ ${ }^{[d]}$ Virbac France, Carros, Alpes-Maritimes, France \\ [e] Virbac América Latina, L'Aigle, Basse-Normandie, France
}

*Corresponding author

e-mail: bruno.lima@virbac.com.br

\section{Abstract}

This study aimed to evaluate the effect of an injectable supplementation in phosphorus, selenium, magnesium, copper and potassium (Fosfosal ${ }^{\circledR}$, Virbac, Brazil) on cyclicity resumption and pregnancy rate of beef cows subjected to FTAI including two dose regimens of eCG (Novormon ${ }^{\circledR}$, Zoetis, Brazil). 594 Bos taurus (Hereford, Angus, or crossbreed) primiparous cows with their calves, at $45 \pm 15 \mathrm{~d}$ postpartum and BCS average of $2.59 \pm 0.02$ (1-thin, 5-obese) from one farm in the central Rio Grande do Sul, were enrolled in this study. On day 1 cows were subjected to an ultrasound exam (rectal linear transducer 5-10Mhz, Mindray DP2200, Shenzhen, China) to assess the ovarian activity. Cows were then randomly allocated to four groups 1 - F300 ( $=160), 2$ - F400 ( $\mathrm{N}=120), 3-\mathrm{C} 300(\mathrm{~N}=160), 4-\mathrm{C} 400(\mathrm{~N}=138)$. F groups were supplemented with 2 injections of trace minerals (Fosfosal, $10 \mathrm{~mL}$, IM - ITM) on days 0 and 9. FTAI protocol included P4impregnated CIDR associated to $2 \mathrm{mg}$ of estradiol benzoate on day 0. On day 9, the CIDR was removed, and cows were dosed with $12.5 \mathrm{mg}$ dinoprost tromethamine and $1 \mathrm{mg}$ estradiol cypionate. According to groups they were allocated to, cows were also injected with either 300 or 400UI of eCG. AI were carried out using frozen semen. Cows found in estrus were identified with a mark of marker stick (Raidl-Maxi). US were used to assess the pregnancy on $\mathrm{d} 41$. Only $34.5 \%$ of cows exhibited a corpus luteum in ovary at the start of the protocol. 374 females were categorized having low BCS $(\leq 2.5)$, the remaining animals having high BCS ( $\geq 2.75$ ). The dose of eCG did not influence the occurrence of estrus and pregnancy rate. Females with a high BCS had significantly $(\mathrm{P}<0.01)$ higher estrus expression $(64.6 \%)$ than those with low BCS 
(56.1\%). The cows that received ITM had higher estrus occurrence $(67.4 \%)$ than control (51.5\%), $(\mathrm{P}<0.05)$. Pregnancy rates in low and high BCS animals were not significantly $(\mathrm{P}=0.09)$ different $(48.3 \%$ and $52.7 \%$, respectively). Pregnancy rate was significantly $(\mathrm{P}<0.01)$ better in ITM treated animals $(53.5 \%)$ than in controls (46.5\%) Across groups, pregnancy rates were similar in F300 (54.1\%) and F400 (52.9), whatever the eCG dosage. We confirm that high BCS favor the expression of estrus in FTAI programs. Additionally two application of FOSFOSAL at implementation and removal of $\mathrm{P} 4$ increase pregnancy rates in primiparous beef cows submitted to FTAI protocol with 300 or 400 UI of eCG. 